\title{
Marco legal del control de drogas en México. Los caminos posibles a
} propósito de la legalización

Arturo Villarreal Palos*

\section{Resumen}

Durante los últimos tiempos se ha venido cuestionando la política mundial en materia de control de drogas y de manera particular se ha propugnado la legalización de la mariguana. En este documento se presenta un panorama general de la política legislativa mexicana sobre el control de drogas -que en lo general es prohibicionista y se fundamenta e inspira en las convenciones internacionales que se han firmado sobre la materia- y se analiza hasta donde se puede avanzar dentro del marco actual, con el ingrediente agregado de los recientes fallos de la Suprema Corte de Justicia de la Nación, que a luz de los derechos humanos, han abierto caminos para el uso recreativo y medicinal de la marihuana. Igualmente se dilucida la cuestión de a quién corresponde legislar en este rubro, concluyéndose que la fijación de la política de salud y salubridad general es una atribución de orden federal, y que si bien las entidades federativas puedan establecer regulaciones particulares sobre esta cuestión, estas no pueden ir más allá ni contravenir las disposiciones del Congreso de la Unión.

Palabras clave: Política control de drogas, México

\section{Legal framework of drug control in Mexico. Roads possible} purpose of probate

\begin{abstract}
In recent times many experts and organizations have questioned the global policy on drug control and particularly aim at least the legalization of marijuana. This document provides an over view of the Mexican legislative policy on drug control, which in general is prohibitive and is based and inspired by the international conventions on drugs. The paper also examines the extent to which progress can be made within the existing framework, with the added ingredient of recent decisions of the

*Universidad de Guadalajara, México.arvipa@gmail.com
\end{abstract}


Supreme Court of Justice of the Nation, which in light of human rights, have opened possibilities for recreation a land medicinal use of marijuana. It also discusses who is responsible for legislating in this area, concluding that setting health policy and general health is an all ocation off federal jurisdiction and that while states may establish special regulations on this issue; they cannot go more beyond or contradict the provisions of Congress.

Key words: Drug, Control, Policy, Mexico.

\section{Sumario:}

1. Introducción. 2. Marco legal. 3. ¿Pueden los Estados legislar en materia de drogas? 4. ¿Hacia dónde se puede avanzar en términos del marco jurídico actual? 5. La Suprema Corte de Justicia de la Nación y el uso recreativo y medicinal de la marihuana. 6. Comentario final. Bibliografía.

\section{Introducción}

Durante los últimos años se ha puesto en evidencia el fracaso de la política mundial en materia de control de drogas y los altos costos que ha generado el régimen de su prohibición.

La literatura especializada que existe es bastante amplia ${ }^{1}$ e incluso la Comisión Latinoamericana sobre Drogas y Democracia, de la que forman parte varios ex Presidentes latinoamericanos, ha sugerido evaluar, con un enfoque de salud

${ }^{1}$ Puedo citar, por ejemplo, el excelente libro de: MANJÓN-CABEZA, Araceli. La solución. La Legalización de las Drogas. $1^{\text {a }}$ edición, España, Editorial Debate, 2012; y el también muy bueno de: AGUILAR CAMÍN, Héctor, GUERRERO, Eduardo, MADRAZO, Alejandro, LAJOUS, Andrés, HERNÁNDEZ TINAJERO, Jorge, CHÁVEZ, Joel y HARO, Dante. Informe Jalisco. Más allá de la guerra de las drogas. $1^{\mathrm{a}}$ edición, México, Editorial Cal y Arena, 2012. Otro documento que reviste de especial interés, en tanto se suscribe por cuatro premios nobel de economía, es: Ending the Drug Wars. Report of the LSE Expert Group on the Economics of Drug Policy. Editado por el Centro IDEAS de la London School of Economics and Political Sciense (LSE) de Londres, Reino Unido. Mayo de 2014. Disponible en Internet [citado 11/11/2014]: http://www.lse.ac.uk/IDEAS/publications/reports/pdf/LSEIDEAS-DRUGS-REPORT-FINAL-WEB.pdf 
pública y haciendo uso de la más avanzada ciencia médica, la conveniencia de descriminalizar la tenencia de marihuana para consumo personal ${ }^{2}$.

El 10 diciembre de 2013, el Poder legislativo Uruguayo aprobó la Ley que permite al Estado el control y regulación de la mariguana, lo que hace que su consumo sea legal en ese país ${ }^{3}$. Y por lo que toca a los Estados Unidos de América, cuyo gobierno federal es el principal promotor de la política restrictiva en materia de consumo de drogas, los Estados de Alaska, Colorado, Washington, Oregón y el Distrito de Columbia, han aprobado el uso recreativo, además de medicinal, de la mariguana, mientras que los Estados de Arizona, California, Connecticut, Hawaii, Illinois, Maine, Maryland, Massachusetts, Michigan, Minnesota, Montana, Nevada, New Hampshire, New Jersey, New México, New York y Rhode Island, permiten su consumo con fines medicinales ${ }^{4}$.

México no ha estado exento de este clima favorable a la legalización de la mariguana y en diversos foros, sobre todo en la capital de la República, se ha insistido sobre el tema. Sin embargo, una cosa es lo deseable y otra lo posible, por lo que en este documento buscamos presentar un panorama general de la política legislativa mexicana sobre el control de drogas -que en lo general es prohibicionista y se fundamenta e inspira en las convenciones internacionales que se han firmado sobre la materia- $y$, asimismo, analizamos hasta donde se puede avanzar en el marco actual, con el ingrediente agregado de los recientes fallos de la Suprema Corte de Justicia de la Nación, que a luz de los

${ }^{2}$ Véase el documento: Drogas y Democracia: Hacia un cambio de paradigma. Declaración de la Comisión Latinoamericana sobre Drogas y Democracia. 2009, pág. 12, Disponible en Internet [citado 10/09/2013]: http://www.drogasedemocracia.org/Arquivos/livro espanhol 04.pdf ${ }^{3}$ Véase la Ley $\mathrm{N}^{\mathrm{o}} 19.172$ aprobada por el Poder Legislativo de la República Oriental del Uruguay el 10 de diciembre de 2013, Disponible en Internet [citado 10/11/2014]:http://archivo.presidencia.gub.uy/sci/leyes/2013/12/cons min_803.pdf Y también el Decreto Reglamentario de la Ley 19.172 expedido por el Presidente de la República del Uruguay, Disponible en [citado 10/11/2014]:http://medios. presidencia.gub.uy/jm_portal/2014/noticias/NO M871/reglamentacion-ley19172.pdf ${ }^{4}$ Sobre esta cuestión, véase la página de "Marijuana Policy Project", una organización, de las más importantes, que trabaja por la reforma de la política sobre la marihuana en los Estados Unidos, Disponible en Internet [citado 12/11/2014]: http://mpp.org/states/ 
derechos humanos, han abierto caminos para el uso recreativo y medicinal de la marihuana.

Igualmente se dilucida la cuestión de a quién corresponde legislar en este rubro, concluyéndose que la fijación de la política de salud y salubridad general es una atribución de orden federal, y que si bien las entidades federativas puedan establecer regulaciones particulares sobre esta cuestión, estas no pueden ir más allá ni contravenir las disposiciones del Congreso de la Unión.

\section{Marco legal}

México tiene una política legislativa prohibicionista en materia de algunas drogas $^{5}$, es decir, sanciona con penas de prisión la producción, procesamiento, venta y posesión salvo casos leves de farmacodependientes o consumidoresde ciertos estupefacientes y psicotrópicos, como son el opio preparado para fumar, la cocaína, la heroína, la mariguana, la cocaína, el ácido lisérgico o LSD, la mezcalina o peyote y los hongos alucinógenos; igualmente, es punible el financiamiento para cualquier actividad relacionada con el tráfico ilícito de estos estupefacientes y psicotrópicos, la conversión o transferencia de fondos a sabiendas de que provienen de esa actividad (lavado de dinero), así como el ocultamiento o encubrimiento de los bienes que produzca.

Existen otros estupefacientes o psicotrópicos cuya producción, comercialización y posesión se sujeta a un estricto control y pueden prescribirse para fines médicos (con receta), como son los casos de la codeína,

\footnotetext{
${ }^{5}$ Según la Norma Oficial Mexicana NOM-028-SSA2-2009, para la prevención, tratamiento y control de las adicciones, el término "Droga" se refiere a cualquier sustancia que previene o cura alguna enfermedad o aumenta el bienestar físico o mental y en farmacología se refiere a cualquier agente químico que altera la bioquímica o algún proceso fisiológico de algún tejido u organismo. La misma Norma señala que la "adicción o dependencia", es el estado psicofísico causado por la interacción de un organismo vivo con un fármaco, alcohol, tabaco u otra droga, caracterizado por modificación del comportamiento y otras reacciones que comprenden siempre un impulso irreprimible por tomar dicha sustancia en forma continua o periódica, a fin de experimentar sus efectos psíquicos y a veces para evitar el malestar producido por la privación.
} 
metadona, morfina, opio en polvo, metanfetaminas, anfetaminas, diazepan, benzodiacepina, entre otros. Sin embargo, su producción y distribución, sin la debida autorización, y su posesión sin receta acarrea sanciones penales.

Finalmente, otras drogas consideradas lícitas o que pueden consumirse sin prescripción, como el alcohol o el tabaco, solo se sujetan a control sanitario y publicitario, aunque de ninguna manera pueden comercializarse bebidas alcohólicas que contengan alcohol etílico en una proporción mayor al 55\% en volumen.

Este marco regulatorio deriva, en una parte muy importante, de los convenios internacionales de la materia que el Estado Mexicano ha suscrito.

Menciono aquí aquellas convenciones internacionales en que nuestro país es parte y se encuentran vigentes.

- Convención para la Supresión del Tráfico Ilícito de Estupefacientes Nocivos y Protocolo de firma, firmado en Ginebra, Suiza, 26 de junio de $1936^{6}$, modificada por el Protocolo que Enmienda los Acuerdos, Convenciones y Protocolos sobre Estupefacientes, concertados en La Haya el 23 de enero de 1912, en Ginebra el 11 de febrero de 1925 y el 19 de febrero de 1925, y el 13 de julio de 1931, en Bangkok el 27 de noviembre de 1931 y en Ginebra el 26 de junio de 1936, adoptado en Lake Success, Nueva York, el 11 de diciembre de $1946^{7}$.

- Convención Única de 1961 sobre Estupefacientes, firmada en Nueva York, el 30 de febrero de $1961^{8}$.

${ }^{6}$ Firma México: 27 de marzo de 1937. Aprobación Senado: 29 de diciembre de 1954. Publicación DOF Aprobación: 28 de febrero de 1955. Entrada en vigor para México: 6 de mayo de 1955. ${ }^{7}$ Firma México: 11 de diciembre de 1946. Aprobación Senado: 29 de diciembre de 1954. Publicación DOF Aprobación: 28 de febrero de 1955. Entrada en vigor para México: 6 de mayo de 1955. ${ }^{8}$ Firma México: 24 de julio de 1961. Aprobación Senado: 29 de diciembre de 1966. Publicación DOF Aprobación: 4 de febrero de 1967. Entrada en vigor para México: 18 de mayo de 1967. 
- Protocolo de Modificación de la Convención Única de 1961 sobre Estupefacientes, firmado en Ginebra, Suiza, el 25 de marzo de 1972 .

- Convenio sobre Sustancias Sicotrópicas firmado en Viena, Austria, el 21 de febrero de $1971^{10}$.

- Convención de las Naciones Unidas contra el Tráfico Ilícito de Estupefacientes y Sustancias Sicotrópicas, firmado en Viena, Austria, el 20 de diciembre de $1988{ }^{11}$.

Esta última convención, por ser la más reciente, concentra la última política internacional en la materia y comprende múltiples disposiciones en materia de control y sanción de actividades relacionadas con las drogas, a las cuales México se sujeta por medio de la Ley General de Salud (LGS).

Me parece importante destacar, sin embargo, que en términos del artículo 3 de esta Convención, dedicado a los "Delitos y sanciones", si bien los Estados parte se obligan a tipificar como delito la posesión, la adquisición o el cultivo de estupefacientes o sustancias sicotrópicas aún para el consumo personal, se señala que en los casos de infracciones de carácter leve, las Partes podrán sustituir la declaración de culpabilidad o la condena por la aplicación de otras medidas tales como las de educación, rehabilitación o reinserción social, así como, cuando el delincuente sea un toxicómano, de tratamiento y pos tratamiento.

Conforme a dicho principio, en materia de consumo personal de drogas, México enuncia una franja muy breve de tolerancia para el farmacodependiente o consumidor, al señalar, en el artículo 478 de la LGS que:

\footnotetext{
${ }^{9}$ Aprobación Senado: 27 de diciembre de 1976. Publicación DOF Aprobación: 20 de enero de 1977. Entrada en vigor para México: 27 de mayo de 1977.

${ }^{10}$ Aprobación Senado: 29 de diciembre de 1972. Publicación DOF Aprobación: 29 de marzo de 1973. Entrada en vigor para México: 16 de agosto de 1976.

${ }^{11}$ Firma de México: 16 febrero 1989. $\square$ Aprobación por el Senado: 30 noviembre 1989. $\square$ Publicación DOF Aprobación: 9 febrero 1990. $\square$ Entrada en vigor para México: 11 noviembre de 1990.
} 
Artículo 478.- El Ministerio Público no ejercerá acción penal por el delito previsto en el artículo anterior [posesión sin fines de comercio o suministro], en contra de quien sea farmacodependiente o consumidor y posea alguno de los narcóticos señalados en la tabla, en igual o inferior cantidad a la prevista en la misma, para su estricto consumo personal y fuera de los lugares señalados en la fracción II del artículo 475 de esta Ley[centros educativos, asistenciales, policiales o de reclusión, o dentro del espacio comprendido en un radio que diste a menos de trescientos metros de los límites de la colindancia del mismo con quienes a ellos acudan]. La autoridad ministerial informará al consumidor la ubicación de las instituciones o centros para el tratamiento médico o de orientación para la prevención de la farmacodependencia.

El Ministerio Público hará reporte del no ejercicio de la acción penal a la autoridad sanitaria de la entidad federativa donde se adopte la resolución con el propósito de que ésta promueva la correspondiente orientación médica o de prevención. La información recibida por la autoridad sanitaria no deberá hacerse pública pero podrá usarse, sin señalar identidades, para fines estadisticos.

Artículo 479.- Para los efectos de este capitulo se entiende que el narcótico está destinado para su estricto e inmediato consumo personal, cuando la cantidad del mismo, en cualquiera de sus formas, derivados o preparaciones no exceda de las previstas en el listado siguiente:

\begin{tabular}{|l|l|}
\hline \multicolumn{2}{|l|}{ Tabla de Orientación de Dosis Máximas de Consumo Personal e Inmediato } \\
\hline Narcótico & Dosis máxima de consumo personal e inmediato \\
\hline Opio & $2 \mathrm{gr}$. \\
\hline $\begin{array}{l}\text { Diacetilmorfina } \\
\text { Heroina }\end{array}$ & $50 \mathrm{mg}$. \\
\hline
\end{tabular}




\begin{tabular}{|c|c|c|}
\hline $\begin{array}{l}\text { Cannabis Sativa, Indica } \\
\text { o Mariguana }\end{array}$ & \multicolumn{2}{|l|}{$5 g r}$. \\
\hline Cocaína & \multicolumn{2}{|l|}{$500 \mathrm{mg}$. } \\
\hline Lisergida (LSD) & \multicolumn{2}{|l|}{$0.015 \mathrm{mg}$. } \\
\hline \multirow{2}{*}{$\begin{array}{l}\text { MDA, } \\
\text { Metilendioxianfetamina }\end{array}$} & $\begin{array}{l}\text { Polvo, granulado } \\
\text { o cristal }\end{array}$ & Tabletas o cápsulas \\
\hline & $40 \mathrm{mg}$. & $\begin{array}{l}\text { Una unidad con peso no } \\
\text { mayor a } 200 \mathrm{mg} \text {. }\end{array}$ \\
\hline $\begin{array}{l}\text { MDMA, } \quad d l-34- \\
\text { metilendioxi-n- } \\
\text { dimetilfeniletilamina }\end{array}$ & $40 \mathrm{mg}$. & $\begin{array}{l}\text { Una unidad con peso no } \\
\text { mayor a } 200 \mathrm{mg} \text {. }\end{array}$ \\
\hline Metanfetamina & $40 \mathrm{mg}$. & $\begin{array}{l}\text { Una unidad con peso no } \\
\text { mayor a } 200 \mathrm{mg} \text {. }\end{array}$ \\
\hline
\end{tabular}

Nótese que el artículo 478 habla del no ejercicio de la acción penal en contra del farmacodependiente o consumidor que posea algún narcótico en las cantidades consideradas como para su estricto consumo personal. Desde mi punto de vista cuando habla de "consumidor" puede referirse a una persona que no sea adicto, lo que abre un breve espacio de tolerancia para el consumo personal.

Tocante al uso de drogas con fines médicos, la LGS distingue entre estupefacientes y psicotrópicos, señalando, en el artículo 237 que queda prohibido en el territorio nacional, todo acto (incluso de prescripción) respecto de las siguientes substancias y vegetales, considerados estupefacientes: opio preparado para fumar, diacetilmorfina o heroína, sus sales o preparados, cannabis sativa, índica y americana o marihuana, papaver somniferum o adormidera, papaver bactreatum y erythroxilon novogratense o coca, en cualquiera de sus formas, derivados o preparaciones.

El artículo 238 indica que solamente para fines de investigación científica, la Secretaría de Salud autorizará a los organismos o instituciones que hayan presentado protocolo de investigación autorizado por aquella dependencia, 
la adquisición de estupefacientes a que se refiere el artículo 237 de la Ley. Dichos organismos e instituciones comunicarán a la Secretaría de Salud el resultado de las investigaciones efectuadas y como se utilizaron.

Esto excluye, desde luego, el uso de la mariguana con fines medicinales en México, a menos que se trate de un protocolo de investigación científica autorizado por la Secretaría de Salud, del cual no tenemos conocimiento que se haya aprobado alguno.

Respecto a los psicotrópicos, el artículo 248 de la LGS señala que queda prohibido todo acto (incluida la prescripción), con relación a las substancias incluidas en la fracción I del artículo 245 (entre ellas, LSD, peyote y hongos alucinógenos).

Pero, conforme al artículo 249, es posible que la Secretaría de Salud autorice la adquisición de las substancias psicotrópicas arriba referidas para fines de investigación científica, para ser entregadas bajo control a organismos o instituciones que hayan presentado protocolo de investigación autorizado, los que a su vez comunicarán a la Secretaría el resultado de las investigaciones efectuadas y cómo se utilizaron.

Conforme al artículo 235, partefinal, de laLGS, existen algunos estupefacientes, como la codeína, metadona, morfina y opio en polvo, que sí pueden utilizarse con fines médicos y prescribirse y tocante a los psicotrópicos, también pueden usarse con fines médicos aquellos que se enlistan en las fracciones II, III y IV del artículo 245, como por ejemplo, metanfetaminas, anfetaminas, diazepan, benzodiacepina, entre otros.

Como podemos verlo, el marco regulatorio nacional e internacional no deja mucho margen para una política liberatoria en materia de posesión, consumo y utilización médica de algunas drogas, que de manera específica son el opio preparado para fumar, la cocaína, la heroína, la mariguana, la cocaína, el ácido lisérgico o LSD, la mezcalina o peyote y los hongos alucinógenos, aunque, conforme el artículo 478 de la LGS, hay una franja muy breve de tolerancia para el consumo personal, que no es objeto de sanción penal. 


\section{3. ¿Pueden los Estados legislar en materia de drogas?}

Como señalamos al principio, en fecha reciente se ha planteado en México un debate sobre la necesidad de un cambio en materia de control de drogas y, de manera específica, se propone la legalización de la marihuana, lo que implicaría su utilización abierta con fines médicos y recreativos, lo cual, si nos atenemos exclusivamente a los tratados internacionales y la legislación nacional vigente, se ve francamente imposible en lo que ve al uso recreativo (salvo casos leves) y en lo tocante al uso medicinal, sí sería posible, a condición de que la Secretaria de Salud autorizara un protocolo de investigación científica y en vista de sus resultados, recomendara modificar la Ley General de Salud, lo que, en el marco de apertura de los recientes fallos de la Suprema Corte de Justicia de la Nación, podría ser probable en el corto plazo.

Sin embargo, se conocen varias iniciativas presentadas en la Asamblea del Distrito Federal a efecto de modificar el marco legal, para que en la capital del país haya una utilización médica o recreativa de la marihuana y también en el Estado de Jalisco se han presentado iniciativas de este tipo, pero todo ello debe verse como utópico, atento a que la autoridad legislativa del Distrito Federal y las autoridades legislativas de los Estados, carecen de las facultades necesarias para regular tal cuestión, según se verá enseguida.

El artículo 4 Constitucional, párrafo cuarto, señala que toda persona tiene derecho a la protección de la salud y que la Ley definirá las bases y modalidades para el acceso a los servicios de salud y establecerá la concurrencia de la Federación y las entidades federativas en materia de salubridad general, conforme a lo que dispone la fracción XVI del artículo 73 de la propia Constitución, la cual señala que el Congreso tiene facultad para dictar leyes, entre otras, sobre salubridad general de la República.

De aquí deriva que siendo la salud una materia concurrente, corresponde al Congreso de la Unión legislar sobre la misma, además de que a este corresponde originariamente legislar en todo el país sobre salubridad general. 
Ahora bien, en el caso específico del Distrito Federal, el artículo 122 Constitucional, apartado C, Base primera, fracción XI, inciso i), otorga a la Asamblea Legislativa del Distrito Federal la facultad de "normar la salud y la asistencia social", en los términos del Estatuto de Gobierno, lo que nos podría llevar a pensar que entonces la Asamblea del Distrito Federal (no así los Estados) sí tiene facultades en esta materia y podría legislar sobre el uso de drogas en la capital del país.

Nótese, sin embargo, que esta facultad para legislar en materia de salud, que es de origen constitucional, debe hacerse, como todas las facultades legislativas de la Asamblea del DF, "en los términos del Estatuto de Gobierno", lo que supone ya una condicionante.

Y así las cosas, si bien el Estatuto de Gobierno del Distrito Federal, en el artículo 42 reitera esta facultad legislativa, en el artículo 44 señala que: "Las leyes y decretos que expida la Asamblea Legislativa del Distrito Federal se sujetarán a lo dispuesto en las leyes generales que dicte el Congreso de la Unión en las materias de función social educativa, salud, asentamientos humanos, protección al ambiente, preservación y restauración del equilibrio ecológico y las demás en que la Constitución Política de los Estados Unidos Mexicanos determine materias concurrente.

Esto significa que la función legislativa de la Asamblea en materia de salud esta sujeta a lo que diga la Ley General de Salud y no puede contradecirla y, por tanto, no puede establecer un régimen especial de drogas para el Distrito Federal.

De hecho, la Ley de Salud del Distrito Federal, es muy clara, en su artículo 1, en el sentido de que la ley tiene por objeto:

I.- Regular las bases y modalidades para garantizar el acceso a los servicios de salud por parte de la población del Distrito Federal y la competencia del Jefe de Gobierno del Distrito Federal en materia de salubridad local;

II.- Fijar las normas conforme a las cuales el Jefe de Gobierno del Distrito Federal ejercerá sus atribuciones en la prestación de los servicios de 
salubridad general a que se refiere el artículo 13 apartado B) y apartado C) de la Ley General de Salud;

III.- Determinar la estructura administrativa y los mecanismos adecuados para que el Jefe de Gobierno del Distrito Federal participe con la Secretaría de Salud Federal en la prestación de los servicios de salud a que se refieren las fracciones I, III, V, VI, XXIII, XXIV, XXV, XXVI, XXVII, XXVIII y XXIX del artículo $3^{\circ}$ de la Ley General de Salud;

IV.- Establecer los derechos y las obligaciones en materia de salud para la población del Distrito Federal;

V.- Definir los mecanismos para promover la participación de la población en la definición, vigilancia y desarrollo de los programas de salud en el Distrito Federal, y

VI.- Las demás que le señalen otras leyes y disposiciones aplicables.

Como puede verse, la Ley de Salud del Distrito Federal, solo desarrolla y regula facultades en materia de salud que ya establece la Ley General de Salud y no va (ni puede) ir más allá de ella.

Del mismo modo, la Ley de Salud del Estado de Jalisco señala, en su artículo 1, que dicha ley "establece la competencia que, en materia de salud, corresponde al Estado de Jalisco, en los términos de los Arts. $4^{\circ}$ y 73 , de la Constitución Política de los Estados Unidos Mexicanos, y de la Ley General de Salud”, lo que implica su sometimiento a dichas disposiciones.

En resumen, no existe posibilidad jurídica de que la Asamblea legislativa del Distrito Federal o las legislaturas de los Estados modifiquen el régimen actual en materia de control de drogas, para crear un régimen especial o específico para sus entidades federativas, ya que, como lo vimos arriba, se trata de una atribución del Congreso de la Unión, que es el que fija la política en esta materia. 


\section{4. ¿Hacia dónde se puede avanzar en términos del marco jurídico actual?}

Como comentamos al inicio de este documento, el marco internacional sobre el control de drogas es muy restrictivo en cuanto a su producción, tenencia y uso, lo que dificulta tener una marco regulatorio que permita un uso abierto de todas o alguna drogas, pues ello implicaría la despenalización de su producción, comercialización y consumo, lo que pugna con los tratados internacionales. Con ello quiero referirme a que en el marco actual y ateniéndonos exclusivamente a ese marco, es prácticamente imposible legalizar el consumo de la mariguana y otras drogas.

Me parece, sin embargo, que acorde a las Convenciones Internacionales es posible que la respuesta del Estado frente a los consumidores y adictos, no necesariamente transite por la vía penal.

La Convención Única de 1961 sobre Estupefacientes, enmendada por el Protocolo de 1972, en su artículo 36, inciso 1, parte a), dedicado a las Disposiciones Penales, contiene un precepto de orden genérico por el que los Estados Parte se comprometen a adoptar las medidas necesarias para que el cultivo, producción, fabricación, extracción, preparación, posesión, transporte, importación y exportación de estupefacientes, se consideren como delitos si se cometen intencionalmente y que los delitos graves sean castigados en forma adecuada, especialmente con penas de prisión u otras penas de privación de libertad.

No obstante, en la parte b) de ese mismo artículo e inciso, se señala que cuando las personas que hagan uso indebido de estupefacientes hayan cometido esos delitos, las partes podrán, en vez de declararlas culpables o de sancionarlas penalmente, o además de declararlas culpables o de sancionarlas, someterlas a medidas de tratamiento, educación, pos tratamiento, rehabilitación y readaptación social, de conformidad con lo dispuesto en el párrafo 1 del artículo 38, que se refiere precisamente a que las partes prestaran atención especial a la prevención del uso indebido de estupefacientes y a la pronta identificación, tratamiento, educación, pos tratamiento, rehabilitación y readaptación social de las personas afectadas. 
Puede verse entonces como, conforme a esta Convención, un consumidor ocasional o un adicto que fuera detenido con un estupefaciente, marihuana, por ejemplo, incluso con una cantidad mayor a la necesaria para el consumo personal e inmediato, podría verse no sancionado penalmente, a condición de someterse a medidas de tratamiento, educación, pos tratamiento, rehabilitación y readaptación social, según el lenguaje de la Convención.

Por su parte, el Convenio sobre Sustancias Sicotrópicas de 1971, tiene una normativa similar, en el artículo 22, Disposiciones Penales, al señalar, en el inciso 1, parte a) que cada parte considerará como delito, si se comete intencionalmente, todo acto contrario a cualquier ley o reglamento que se adopte en cumplimiento de las obligaciones impuestas por el Convenio y dispondrá lo necesario para que los delitos graves sean sancionados en forma adecuada, especialmente con penas de prisión u otras penas de privación de libertad.

No obstante, en la parte b) de ese mismo artículo e inciso, se señala que cuando las personas que hagan uso indebido de sustancias sicotrópicas hayan cometido esos delitos, las partes podrán, en vez de declararlas culpables o de sancionarlas penalmente, o además de sancionarlas, someterlas a medidas de tratamiento, educación, pos tratamiento, rehabilitación y readaptación social, de conformidad con lo dispuesto en el párrafo 1 del artículo 20. Como vemos, una disposición igual a la Convención de Estupefacientes.

Ahora bien, la Convención de las Naciones Unidas contra el Tráfico Ilícito de Estupefacientes y Sustancias Sicotrópicas de 1988, en su artículo 3, Delitos y Sanciones, contiene el compromiso de los Estados Parte de sancionar penalmente una larga lista de actividades relacionadas con estupefacientes y sicotrópicos, tales como su producción, fabricación, extracción, preparación, oferta, venta, distribución, transportación y la entrega, conversión u ocultamiento de fondos provenientes de esas actividades ilícitas, entre otras.

Asimismo, la parte 2 de este artículo, expresamente contempla el compromiso de tipificar como delito la posesión, la adquisición o el cultivo de estupefacientes o sustancias sicotrópicas para el consumo personal, en contra de lo dispuesto 
en la Convención de 1961, en la Convención de 1961 en su forma enmendada o en el Convenio de 1971.

No obstante, la parte 3 de este artículo, en su inciso c) establece que en los casos apropiados de infracciones de carácter leve, las partes podrán sustituir la declaración de culpabilidad o la condena por la aplicación de otras medidas tales como las de educación, rehabilitación o reinserción social, así como, cuando el delincuente sea un toxicómano, de tratamiento y pos tratamiento, y que (inciso d) las partes podrán, ya sea a título sustitución de la declaración de culpabilidad o de la condena por un delito tipificado de conformidad con el párrafo 2 del artículo 3 o como complemento de dicha declaración de culpabilidad o de dicha condena, disponer medidas de tratamiento, educación, pos tratamiento, rehabilitación o reinserción social del delincuente.

Como vemos, también esta Convención da la posibilidad de otorgar un trato no penal a cierto grupo de consumidores que cometan infracciones de carácter leve y sustituir la "declaración de culpabilidad o condena" para otro grupo de consumidores, a condición de que en ambos casos se sometan a medidas de tratamiento, educación, pos tratamiento, rehabilitación o reinserción social.

Podemos concluir entonces que, conforme a las normas actuales, es posible dar una respuesta y trato no penal a un cierto tipo de consumidores leves, y a otro grupo de consumidores, que pudieran poseer cantidades mayores a las señaladas para uso personal, la oportunidad de suspender el proceso a prueba, a condición de que en ambos casos se sometan a determinadas medidas de orientación o tratamiento.

Algunos países han avanzado dentro de este marco y un caso especialmente interesante es el de Portugal, donde el $1^{\circ}$ de julio de 2001 se expidió una ley que "descriminaliza" la compra, posesión y consumo de cualquier tipo de droga para uso personal, entendiendo por tal la cantidad suficiente para el consumo de 10 días. Esta "descriminalización" no hace legal la posesión de droga, pero si la convierte en una falta administrativa y así, los infractores son puestos a disposición de la "Comisión para Disuasión de la Adicción a las Drogas". Los consumidores no adictos pueden ser sancionados con una 
multa de alrededor de 25 euros o en ocasiones con una advertencia. En otros casos, las sanciones son suspendidas a condición de que el sujeto se someta a un tratamiento. La política seguida por Portugal se ha considerado exitosa, pues los índices de consumo de drogas en lugar de aumentar han venido disminuyendo, además de que se evita en todo el gasto que el sistema de sanción penal implica y la propia exposición de los infractores a ese sistema ${ }^{12}$

Otros aspecto en el cual se puede transitar el marco actual, es el relativo al uso médico y científico de los estupefacientes y psicotrópicos, pues las Convenciones Internacionales de Estupefacientes de 1961 (artículo 4) y de Sustancias Sicotrópicas de 1971 (artículo 5), no lo prohíben, sino al contrario, expresamente establecen que las partes adoptarán todas las medidas legislativas y administrativas que puedan ser necesarias para limitar exclusivamente la producción, la fabricación, la exportación, la importación, la distribución, el comercio, el uso y la posesión de estupefacientes y sicotrópicos a los fines médicos y científicos.

Conforme a ello, México podría autorizar protocolos de investigación científica y de encontrarse procedente, autorizar el uso médico de la marihuana.

Si nos atenemos exclusivamente al marco jurídico que actualmente se aplica en México, estimo que hasta aquí es donde podríamos avanzar. Sin embargo, los recientes fallos de la Suprema Corte de Justicia de la Nación han abierto un camino inesperado, que a la luz de los derechos humanos, puede llevarnos a la autorización del uso recreativo y con fines médicos de la marihuana.

\section{La Suprema Corte de Justicia de la Nación y el uso recreativo y medicinal de la marihuana.}

E13 de noviembre de 2015, la Primera Sala de la Suprema Corte de Justicia de la Nación declaró inconstitucionales los artículos 235, 237, 245, 247 y 248, todos

\footnotetext{
${ }^{12}$ Sobre el particular, véase: GREENWALD, Glenn. Drug Decriminalization in Portugal. Lessons for creating fair and successful drug policies. United States of America, Cato Institute, 2009, págs. 2, 3, 11 y 28.
} 
de la Ley General de Salud, en las porciones que establecen una prohibición para que la Secretaría de Salud emita autorizaciones para la realización de los actos relacionados con el consumo personal con fines recreativos (sembrar, cultivar, cosechar, preparar, poseer, transportar), en relación única y exclusivamente con el estupefaciente "cannabis" (sativa, índica y americana o mariguana, su resina, preparados y semillas) y el psicotrópico "THC" (tetrahidrocannabinol), en conjunto conocidos como "marihuana", declaratoria de inconstitucionalidad que no supone en ningún caso autorización para realizar actos de comercio, suministro o cualquier otro que se refiera a la enajenación y/o distribución de las substancias antes aludidas. ${ }^{13}$

La Primera Sala, en términos del proyecto del Ministro ponente, Arturo Zaldívar Lelo de Larrea, consideró que una prohibición absoluta del consumo de la marihuana no sólo es innecesaria, al existir medios alternativos igualmente idóneos que afectan en un menor grado el derecho al libre desarrollo de la personalidad, sino que además es desproporcionada en estricto sentido, toda vez que genera una protección mínima a la salud y orden público, frente a la intensa intervención al derecho de las personas a decidir qué actividades lúdicas desean realizar.

Si bien la Primera Sala no minimizó los daños que puede ocasionar la marihuana en el consumidor mayor de edad, entiende que la decisión sobre su uso sólo le corresponde tomarla a cada individuo y, por tanto, considera que pertenece al estricto ámbito de la autonomía individual, protegido por el derecho al libre desarrollo de la personalidad, la posibilidad de decidir

\footnotetext{
${ }^{13}$ Se trató de una decisión por cuatro votos a favor de los Ministros Arturo Zaldívar Lelo de Larrea, José Ramón Cossío Díaz, Alfredo Gutiérrez Ortiz Mena y Olga María Sánchez Cordero. El Ministro Jorge Mario Pardo Rebolledo votó en contra del proyecto, pero no por estar en contra de los razonamientos vertidos, sino porque a su juicio dejaba sin resolver la cuestión de la adquisición primigenia (la semilla de la marihuana, por ejemplo), la cual seguiría siendo delictuosa. La "Versión de la sesión pública ordinaria de la Primera Sala de la Suprema Corte de Justicia de la Nación, celebrada el miércoles 03 de noviembre de 2015, donde se resolvió el amparo en revisión 237/2014", puede ser consultada en la siguiente dirección de internet [citado 12/11/2015]: https://es.scribd.com/doc/288560160/Version-dela-sesion-publica-de-La-Primera-Sala-donde-se-resolvio-avalar-el-consumo-y-la-siembrade-la-mariguana
} 
responsablemente si desea experimentar los efectos de esa sustancia, a pesar de los daños que esta actividad puede generarle a una persona ${ }^{14}$.

En los hechos, la aludida resolución de la Suprema Corte supone una permisión para el uso recreativo de la marihuana, incluida su posesión y transporte y para los actos previos a su consumición, como son su siembra, cultivo, cosecha y preparación, en las cantidades que resulten necesarias para el autoconsumo.

Esta permisión, sin embargo, es solo aplicable a las cuatro personas que solicitaron el amparo y protección de la justicia federal, pero seguramente y como consecuencia de las sucesivas peticiones de amparo que sobrevendrán, pronto la Suprema Corte establecerá una jurisprudencia por reiteración, que hará obligatorio este criterio para todas las autoridades judiciales del país y, en ese caso, bastará con que cualquier ciudadano acuda ante cualquiera de los Jueces de Distrito de la nación, para que este le conceda autorización para el uso lúdico o recreativo de la marihuana.

Hay que considerar, sin embargo, que, en términos del artículo 102, fracción II, segundo párrafo, de la Constitución Política y 231 de la Ley de Amparo, cuando por segunda ocasión en un juicio de amparo indirecto en revisión (como es el caso) se resuelva la inconstitucionalidad de una norma general (como lo son las previstas en la Ley General de Salud), la Suprema Corte de Justicia de la Nación lo deberá informar a la autoridad emisora correspondiente (en este caso, el Congreso de la Unión).

Asimismo, de acuerdo al citado artículo 102, fracción II, tercer párrafo, de la Constitución Política y 232 y 234 y de la Ley de Amparo, cuando el pleno o las salas de la Suprema Corte de Justicia de la Nación, en los juicios de amparo indirecto en revisión, establezcan jurisprudencia por reiteración, en la cual se determine la inconstitucionalidad de la misma norma general, se procederá a notificar al órgano emisor de la norma y transcurrido el plazo de 90 días naturales sin que se modifique o derogue la norma declarada

\footnotetext{
${ }^{14} \mathrm{El}$ proyecto de sentencia del Ministro Arturo Zaldívar Lelo de Larrea en el amparo en revisión 237/2014, puede ser consultado en la siguiente dirección de internet [citado 12/11/2015]:http://issuu.com/lasillarota/docs/mariguana_corte_p
} 
inconstitucional, el pleno de la Suprema Corte de Justicia de la Nación emitirá la declaratoria general de inconstitucionalidad correspondiente, siempre que hubiera sido aprobada por mayoría de cuando menos ocho votos, la cual será obligatoria, tendrá efectos generales y establecerá la fecha a partir de la cual surtirá sus efectos y los alcances y las condiciones de la declaratoria de inconstitucionalidad.

En resumen y en caso de no tomarse medidas legislativas con antelación, puede llegarse el caso de que la permisión general del consumo de la marihuana para fines lúdicos o recreativos en México, pueda darse por vía de la declaratoria de inconstitucionalidad por parte de la Suprema Corte de Justicia de la Nación.

A nivel medicinal, en septiembre de 2015, el Juez Tercero de Distrito en Materia Administrativa en el Distrito Federal, autorizó la importación de una sustancia derivada del cannabis como tratamiento médico, para una niña que padece un síndrome que la hace sufrir hasta 400 crisis de epilepsia diarias. Esta niña podría ser la primera mexicana en utilizar legalmente mariguana con fines medicinales.

\section{Comentario final}

Los anteriores fallos de la Suprema Corte han abierto un camino inesperado para el uso recreativo y medicinal de la marihuana en México. $\mathrm{Y}$, en muchos sentidos era un cambio esperado y necesario. Sin embargo, es vital sentarnos a pensar en los cambios subsiguientes, pues aun suponiendo que los consumidores actuales pudieran llegar a ser autosuficientes cultivando su propio estupefaciente, ello no significaría la desaparición de las organizaciones criminales dedicadas al tráfico de la marihuana en México, pues estas seguirían viendo con interés el atractivo mercado norteamericano y que, según Guillermo Valdés, representa 11 millones de consumidores (50\% del mercado estadounidense) $)^{15}$.

${ }^{15}$ Véase el artículo de VALDEZ CASTELLANOS, Guillermo. "Mariguana, impactos probables. En Periódico Milenio, México, D.F., 11 de noviembre de 2015. 
De ahí la necesidad de realizar un cambio consensuado con la comunidad internacional.

Pero por lo pronto, esperaremos a ver los resultados del amplio debate sobre el consumo de la marihuana que, en noviembre de 2015, el presidente Enrique Peña Nieto ordenó realizar a la Secretaría de Gobernación. La suerte está echada, pero a la luz de los acontecimientos recientes, parece que no hay vuelta atrás.

\section{Bibliografía}

\section{2}


Ending the Drug Wars. Report of the LSE Expert Group on the Economics of Drug Policy. Editado por el Centro IDEAS de la London School of Economics and Political Sciense (LSE) de Londres, Reino Unido. Mayo de 2014. Disponible en Internet [citado 11/11/2014]: http://www. lse.ac.uk/IDEAS/publications/reports/pdf/LSE-IDEASDRUGS-REPORT-FINAL-WEB.pdf

Proyecto de sentencia en el amparo en revisión 237/2014. Primera Sala de la Suprema Corte de Justicia de la Nación. Ministro Ponente: Arturo Zaldívar Lelo de Larrea. Puede ser consultado en la siguiente dirección de internet [citado 12/11/2015]: http://issuu.com/lasillarota/docs/mariguana corte $p$

Versión de la sesión pública ordinaria de la Primera Sala de la Suprema Corte de Justicia de la Nación, celebrada el miércoles 03 de noviembre de 2015, donde se resolvió el amparo en revisión 237/2014. Puede ser consultada en la siguiente dirección de internet [citado 12/11/2015]: https:// es.scribd.com/doc/288560160/Version-de-la-sesionpublica-de-La-Primera-Sala-donde-se-resolvio-avalar-elconsumo-y-la-siembra-de-la-mariguana

\section{Legislación:}

Constitución Política de los Estados Unidos Mexicanos

Ley General de Salud (México)

Ley de Salud en el Distrito Federal (México) infactible

Norma Oficial Mexicana NOM-028-SSA2-2009, para la prevención, tratamiento y control de las adicciones

Ley $\mathrm{N}^{\circ} 19.172$ aprobada por el Poder Legislativo de la República Oriental del Uruguay el 10 de diciembre de 2013, Disponible en Internet [citado 10/11/2014]:http://archivo. presidencia.gub.uy/sci/leyes/2013/12/cons_min_803.pdf

Decreto Reglamentario de la Ley 19.172 expedido por el Presidente de la República del Uruguay, Disponible 


\section{Bibliografía}

en Internet [citado 10/11/2014]: http://medios. presidencia.gub.uy/jm_portal/2014/noticias/NO_M871/ reglamentacion-ley19172.pdf

\section{Convenciones internacionales}

Convención para la Supresión del Tráfico Ilícito de Estupefacientes Nocivos y Protocolo de firma, firmado en Ginebra, Suiza, 26 de junio de 1936, modificada por el Protocolo del 11 de diciembre de 1946.

Convención Única de 1961 sobre Estupefacientes, firmada en Nueva York, el 30 de febrero de 1961.

Protocolo de Modificación de la Convención Única de 1961 sobre Estupefacientes, firmado en Ginebra, Suiza, el 25 de marzo de 1972.

Convenio sobre Sustancias Sicotrópicas firmado en Viena, Austria, el 21 de febrero de 1971.

Convención de las Naciones Unidas contra el Tráfico Ilícito de Estupefacientes y Sustancias Sicotrópicas, firmado en Viena, Austria, el 20 de diciembre de 1988. 